\title{
Literatura de patíbulo en el siglo XIX colombiano: la restauración de las conductas*
}

\author{
DOI: https://doi.org/10.18046/recs.i3o.3563 \\ Gallows Literature in the Colombian Nineteenth Century: \\ The Restoration of Behaviors
}

\author{
Alfonso Rubio ${ }^{* *}$ \\ Universidad del Valle (Cali, Colombia)
}

${ }^{*}$ Este artículo es resultado del proyecto de investigación, financiado con fondos propios y todavía en curso, titulado "Lite-
ratura de patíbulo en el siglo XIX colombiano". Artículo de investigación recibido el 23.05.2019 y aceptado el 06.11.2019.
${ }^{* *}$ Docente del Departamento de Historia de la Universidad del Valle (Colombia). Miembro del Grupo de investigación
Nación-Cultura-Memoria. Correo electrónico: alfonso.rubio@correounivalle.edu.co ORCID: https://orcid.org/oooo-
0002-5782-5092 


\section{Cómo citar/How to cite}

Rubio, Alfonso (2020). Literatura de patíbulo en el siglo XIX colombiano: la restauración de las conductas. Revista CS, 30, 277-305. https://doi.org/10.18046/recs.i30.3563 


\section{Resumen}

Desde una metodología de análisis documental, centrada en representativas muestras que tuvieron origen en la ejecución pública de los sentenciados a muerte en el patíbulo, este artículo tiene como objetivo acercarse a la función que estos escritos mantuvieron durante el siglo XIX colombiano, en el contexto de un naciente régimen republicano y su sistema judicial. En la terminología propuesta por Hans-Jürgen Lüsebrink, las hemos catalogado como "literatura de patíbulo" que, en su variada gama de impresos como sentencias judiciales o cartas de despedida, ofrecían relatos relativos al reo sentenciado a muerte y a los rituales de ejecución concebidos como mecanismos del Estado que reforzaban su capacidad de ejercer justicia. Las sentencias ejecutivas mostraban un lenguaje que nos ha permitido compararlas con el mensaje moralizante, cuya finalidad tenía que ver con la restauración de las conductas en los romances de crímenes españoles, pues el origen literario y las intenciones son similares.

PALABRAS CLAVE:

literatura de patíbulo, Colombia, siglo XIX, código penal

This article aims to approach the role these writings maintained during the nineteenth century in the context of a rising republican regime and its judicial system from a methodology of documentary analysis. It is focused on representative samples originated in the public execution of those sentenced to death on the gallows. In the terminology proposed by Hans-Jürgen Lüsebrink we have categorized them as "Gallows literature" which, in its varied range of forms, such as court judgments or farewell letters, provided stories concerning the defendant sentenced to death and the rituals of execution conceived as State mechanisms that strengthened its capacity to exercise justice. The executive judgments showed a language that has allowed us to compare them with the moralizing message, whose purpose had to do with the restoration of the behaviors in the romances of Spanish crimes since the literary origin and intentions are similar.

\section{KEYWORDS:}

Gallows Literature, Colombia, Nineteenth Century, Criminal Code 



\section{Introducción}

Sin ser todavía categorizada como literatura de patíbulo, en el siglo XIX colombiano existió una variedad de tipologías documentales relacionada con la ejecución de los reos que, por sus crímenes cometidos, se llevaba a cabo ante un patíbulo ceremonial. Los archivos colombianos custodian ejemplos que, tomados como indicios, podemos conectarlos con escritos homólogos del contexto europeo, donde surgen este tipo de expresiones. Una literatura que en el ámbito latinoamericano en general todavía no se ha singularizado y, tal vez por ello, permanezca sin analizarse, tanto desde el punto de vista de la caracterización de los géneros literarios, como desde el derecho procesal, una disciplina íntimamente ligada a la producción de esta variedad editorial.

Hay una literatura de "recuerdos", de "memorias", de "reminiscencias", una literatura costumbrista, podríamos llamarla, que aporta indicios de la circulación de "hojas sueltas" o "papeles" relacionados con la ejecución de los reos ante el patíbulo público. Pero no se han emprendido estudios que delimiten y contextualicen este conjunto de impresos y, al mismo tiempo, aborden sus contenidos y sus modos de producción, circulación y consumo. Este texto pretende ser un acercamiento al tema y, para ello, tomamos como modelos representativos ciertos escritos que se ajustan a las características materiales generales con que se dieron, escritos de una sola hoja suelta, impresos únicamente por su anverso que necesariamente hay que conectar con la cultura jurídica del momento y su mensaje moral pretendido.

La última hora de un infeliz en capilla es el título de uno de ellos. Está impreso por José Ayarza y fechado, en Bogotá, el 28 de junio de 1839. Comienza con la voz anónima de alguien que da testimonio de lo que seguidamente va a narrar ("El que esto escribe puede dar testimonio de que lo vio y oyó, y su nombre nada importa"). La narración se detiene en los "sentimientos" del joven Narciso González, quien dio "muerte alevosa" a Mauricio Hogan. Para dar mayor veracidad, con la primera persona del singular, el narrador anónimo introduce el relato de Narciso González ("Yo le he oído pronunciar entre jemidos [sic] estas sentidas quejas"). Las quejas, gráficamente entrecomilladas de principio a fin, representan la voz personal del criminal, y abarcan prácticamente la totalidad del escrito. Así comienzan: "Mi destino me conduce a la muerte, nací para la desgracia y muero en el oprobio...”. La frase, lapidaria, es un recurso inicial que intenta seducir al lector haciéndole partícipe de la desgracia que está sufriendo González como reo que es. Son los últimos momentos de un "infeliz" que se encuentra "en capilla”, en estado de confesión antes del "estallido del fusil" que le hará morir ante "un inmenso pueblo" cuya ejecución "presenciará". Es una carta de arrepentimiento público ante Dios y los ciudadanos, donde el sentenciado pide "perdón por los escándalos de [su] vida licenciosa" y, 
para hallar la felicidad en la "eternidad" y "no caer en un abismo espantoso", le es indispensable "ir acompañado de la luz del evangelio".

Este texto podemos compararlo con otro similar, titulado El ajusticiado a sus conciudadanos (1846), para dar cuenta de algunas características relacionadas con su creación, que son idénticas a las que se encuentran en el texto del que más adelante damos cuenta y en el que nos centraremos, titulado $A$ mis compatriotas (1828). Los dos textos referenciados (La última hora de un infeliz en capilla y El ajusticiado a sus conciudadanos) evidencian que sus autores han tenido que documentarse oralmente, mediante el testimonio directo de los reos, rastreando sus pasados. Ambos representan la voz del reo en primera persona, y el segundo reproduce la voz de Teodoro Rivas, quien trata de "hermano" a Narciso González, el reo del primer impreso fechado en 1839. Con él se compara: “(...) y mi hermano tuvo la desgracia de dar muerte al Sr. Mauricio Hogan, por una represión, y yo a mi mujer por no tolerarle una contradicción, y ambos hemos sido víctimas del error, y ambos destinados a morir afrentosamente en un patíbulo".

Los reos protagonistas (Narciso González y Teodoro Rivas) hablan de su orfandad en tono de desgracia, cuando, fruto de una persecución política, condenaron a muerte a sus padres por ofrecer hospitalidad a quien "llevaba el nombre de español y no se convertía en su perseguidor". Ambos hablan del régimen educativo viciado que, con el nuevo Estado republicano, posibilita la formación a través del "ejemplo libertino", no da "entrada en él ni a Dios ni a su ley sagrada" y "difunde en todas las clases del Estado el odio a Dios, el desprecio por todas las prácticas religiosas", el “ateísmo", el "materialismo" y la "subversión de todo orden”.

Los dos textos son un arrepentimiento público por las faltas criminales que los reos reconocen mientras culpan a un nuevo régimen político de ello, por inculcar “el principio de rebelión a Dios y a su Patria”. Además de ser una confesión pública y pedir perdón ante "Jesucristo mi Dios, mi Redentor y mi Juez", los escritos apelan a los ciudadanos ("mis hermanos") mediante "un público testimonio contra la falsa doctrina con que se ha inmoralizado al público". El sentido político, disfrazado de moral cristiana en el momento de la confesión y el arrepentimiento antes de sus ejecuciones, recorre los textos con expresiones y vocabulario similares: "Mi hora se acerca" y "Ya ha sonado la hora fatal"; "Me dirijo por mis propios pies a pulsar las puertas de la eternidad" y "Eternidad eternidad, ya se abrieron tus puertas", etc.

Todo hace pensar que, si no es el mismo el autor de los dos escritos, este tipo de literatura de patíbulo estaba ya arraigada en Bogotá a fines de la primera mitad del siglo XIX. Las pasiones políticas, los odios ideológicos, además de una criminalidad generalizada, aumentaron notablemente la pena de último suplicio, y de ella dio buena cuenta la opinión pública de la prensa, bien a su favor, porque "hace desapa- 
recer de sobre la tierra a personas que han funcionado subalternamente atentando contra la seguridad", o bien en su contra, porque los "rasgos generosos de clemencia" cimentan mejor "por medio de la unión (...) los fundamentos de la República, que no los castigos y severidades espantosas" (Triunfó la lei [Los patriotas comprometidos], 1835; El interés patriótico, 1833$)^{1}$.

Estas cartas públicas de los reos en los momentos previos a su ejecución están estructuradas bajo unos mismos patrones estilísticos, y sus autores son escritores dedicados a ello, conocen las técnicas literarias para hacerlas atractivas al público. Su difusión estaba destinada a la venta y sobre la función comercial que rodeaba su elaboración sabemos que la carta de 1839 lleva, en nota a pie de página, la siguiente indicación: "Deducidos los gastos de este papel, el residuo se invertirá en misas por el alma de González". Y el escrito de 1846, en su apartado final, después del nombre del reo resaltado gráficamente y antes de la fecha, señala: "El producto de este papel se destina para sufragios del alma del reo". Además de poder ser un hecho cierto el que ambas cartas indican, estas notas podían funcionar también de reclamo para unas ventas destinadas posiblemente a fines particulares.

El texto en el que luego nos detendremos es un escrito más breve y preciso que los anteriores. Se trata de una carta pública que no llega a abarcar la totalidad del anverso de una página. Es la última confesión de José Manuel Almeida, un reo condenado a muerte que, pocos días antes de que se ejecute su sentencia públicamente, decide escribir una "despedida" pidiendo misericordia para la salvación de su alma, apelando a la compasión de sus potenciales lectores y oyentes, en caso de ser leído ante auditorios públicos. Un escrito destinado a su difusión, posiblemente en los días previos y el mismo día de la ejecución; está impreso en los talleres de Bruno Espinosa y se fecha en Bogotá, en 24 de junio de $1828^{2}$. Está encabezado por el significativo título, en los comienzos republicanos, de A mis compatriotas, un título con el que, además de recordar las que fueron conocidas acciones combativas de su familia, los Almeida, en favor de la independencia, intenta hacer un llamado público a la complicidad piadosa de los lectores (Díaz-Díaz, 1962).

Directamente relacionada con lo que Hans-Jürgen Lüsebrink (1982: 285-301) ha denominado "literatura de patíbulo", estas "despedidas de reos" o "últimas confesiones" forman parte de los engranajes documentales que, bien a iniciativa

1. A mitad del siglo XIX, la situación en Bogotá hizo hablar al cronista José María Cordovez Moure (1957: 89) de una "temporada de crímenes [que] debe llamarse, sin exageración, del terror". Citamos la obra titulada Reminiscencias de Santaféy Bogotá, cuya primera edición es de 1893.

2. Sobre la figura de Antonio Espinosa y sus hijos, Bruno y Diego, como tipógrafos, ver Rubio y Murillo-Sandoval (2017: 57-67). 
oficial o privada, daban cuenta de concretos rituales de ejecución. Las ejecuciones públicas, concebidas como ceremonias o espectáculos aleccionadores y propagandísticos, fueron mecanismos de los Estados que reforzaban su poder. Intentaban mostrar su capacidad de mantener el orden público y de ejercer justicia y, al mismo tiempo, disuadían a sus ciudadanos de tomar el ejemplo de los actos criminales que habían llevado al reo al patíbulo. En un momento como el de 1828, donde la recién proclamada República de Colombia, de 1821, estaba definiendo sus nuevas estructuras políticas, administrativas y judiciales, sus decisiones en materia de justicia debían ser firmes y modélicas para legitimar un nuevo orden y hacer sentir que su sostenimiento era posible. La concurrencia masiva del público el día de la ejecución suponía, por tanto, un elemento fundamental para el éxito de estos fines políticos.

La literatura de patíbulo, por medio de sus múltiples variantes de impresos, ofrecía relatos referentes al reo sentenciado: los crímenes que lo habían condenado, su sentencia ejecutiva, su confesión, sus últimas palabras. Los asuntos fueron muy diversos y constituyó un "subgénero editorial" popular de amplia difusión en Europa entre los siglos XVII y XIX33. Este tipo de impresos podía anunciar la ejecución con la narración de los hechos delictivos y sentencia del reo, animando al público a concurrir al patíbulo. La difusión y contemplación de la ceremonia de ejecución multiplicaba así la resonancia del castigo con el que se había condenado a los culpables y la propaganda pretendida por los Estados tras la eficacia de sus justicias.

La literatura de cordel ("romances o relaciones de reos", "coplas de ajusticiados") en España, la complainte criminelle y la relation en Francia, o las execution ballads en Inglaterra, son algunos de los principales géneros de la literatura de patíbulo. Juan Gomis (2016) relaciona una nómina de autores relevantes en el estudio de este tipo de literatura europea, en relación tanto a la pena de muerte como a determinados conjuntos impresos; mientras que Pascal Bastien (2006), señala que el autor francés inserta los géneros mencionados en un conjunto editorial mucho más amplio vinculado a la ejecución. Junto a las "baladas" y las "relaciones", desde finales del XVII, comienza a publicitarse en Londres una literatura jurídica oficial como los proceeding, que relataban causas juzgadas. En París, se imprimieron las sentencias de muerte o arrêts de mort, que se sumaron a las relations, complaintes, canards y otras hojas sueltas

3. Aunque no es una cuestión aquí la de hablar de las consideraciones de la "cultura popular" como concepto historiográfico, sí es oportuna la observación de Roger Chartier (1994), en el sentido de poder pensar la relación de los textos ambulantes y el mundo social donde se mueven al margen del Antiguo Régimen. Esto, dice, supone dos gestiones complementarias: la primera sugiere una lectura de la "literatura popular" como un repertorio de modelos de comportamiento; la segunda, centrarse en la historia social de los usos y de las comprensiones de los textos por parte de sus lectores. 
o volantes tipo "Circonstances effroyables", "Horrible crime" o "Histoire extraordinaire", destinadas a difundirse en los muros de las calles o en formato octavo.

A este tipo de impresos, que remitían al suplicio final del criminal, en Francia e Inglaterra se suma un tipo editorial que recogía las últimas palabras del condenado, los last dying speeches y los procès-verbaux d'exécution o testaments de mort. En Londres, la voz del reo se hizo pública mediante la imprenta y fue muy demandada. El procedimiento general fue el de escribir el texto en prisión, se leía en voz alta delante del patíbulo y se enviaba al capellán para que ordenara su impresión (Gomis, 2016: 9-33). Las muestras que encontramos en el Fondo Anselmo Pineda de la Biblioteca Nacional de Colombia demuestran, para el caso concreto de las que denominamos "cartas de confesión de reos", que estas se imprimían antes de su ejecución.

Pascal Bastien (2006: 62) encuentra, para su estudio, los géneros antes relacionados en los fondos documentales de los Archivos Nacionales de París, impresos informativos del Estado francés después del Antiguo Régimen hasta el siglo XIX: “c'est dans ce fonds que sont conservées les nombreuses liasses de jugements et d'arrêts criminels, de placards, de mémoires, de canards et de gravures que rassemblèrent d'abord un magistrat du Châtelet de Paris, Thomas-Simon Gueullette". Este magistrado fue procurador del rey en Châtelet, desde 1709 hasta su muerte en 1766 , bibliófilo, autor y aficionado de la "literatura ligera". Recibía piezas de muy diverso orden, donde los placards y los arrêts procedían de las relaciones que mantenía con los impresores:

Gueullette put avec Laurent-François, libraire et imprimeur du roi, recevoir une importante série de jugements san savoir à courir les colporteurs pour se les procurer. Quant aux mémoires judiciaires, tout comme les nombreux occasionnels, canards et gravures populaires composant le corpus. (Bastien, 2006: 63) ${ }^{4}$

El coronel Anselmo Pineda (1805-1880) fue un "conservador ilustrado" que mantuvo una activa vida como político, militar, intelectual y coleccionista, creando múltiples vínculos personales que estuvieron repartidos por todo el país gracias a su permanente itinerancia en sus cargos militares y políticos. La historiografía colombiana lo ha relegado a un segundo plano, pero jugó un papel decisivo en el proceso de consolidación estatal durante buena parte del siglo XIX. El coleccionismo mantuvo una relevante función política de progreso en los procesos sociales y culturales del

4. Sobre la literatura testimonial y memorial relacionada con el crimen, fuente para su estudio, ver el capítulo 2 de Bastien (2006: 29-61): "De la lecture à l'écriture: parcourir la littérature de témoignage". Sobre los tribunales y procesos judiciales de criminales en Londres y París, entre los siglos XVI y XVIII, ver Bastien (2011: 23-91). 
siglo XIX y la magnitud de la colección de Anselmo Pineda, conformada por 1379 volúmenes documentales, con más de siete mil piezas; 15 volúmenes de correspondencia y otros relativos a periódicos (1791-1853); proyectos de ley del Antiguo Consejo de Estado; diarios familiares, y documentos del periodo colonial, ha sido y sigue siendo imprescindible, desde el punto de vista tanto del propio coleccionismo como del investigativo, para poder dar cuenta de la formación de un Estado y una identidad nacionals.

Este es el fondo documental que utilizamos para hablar de literatura de patíbulo en Colombia. Es el que todavía permanece insuficientemente investigado, desconociendo, muchas veces, el origen de una tradición de la cultura escrita, de la cual proceden ciertas tipologías documentales a las que, tal vez por su propia singularidad material de ser "hojas sueltas" y su "insignificancia" connotativa, no solemos acercamos.

\section{A mis compatriotas: la carta de despedida de José Manuel Almeida}

Nos detenemos, entonces, en la carta titulada $A$ mis compatriotas, firmada con letras de molde en su final por José Manuel Almeida (1828). El texto parte de la sentencia que lo condena y de esta sentencia o, mejor dicho, de su sumario daremos cuenta después de comentar los rasgos confesionales de esta carta de despedida.

José Manuel Almeida toma como punto de partida la "situación dolorosa" en que se halla, y es ella, según sus palabras, la que le obliga a escribir a sus "compatriotas". Dos son sus objetivos: uno, dirigido al cuidado de sí mismo, tranquilizar su conciencia; y el otro, dirigido al juicio de la opinión pública. Como una última y pública confesión, intenta conseguir su "eterna salvación", que es a la vez una salvación religiosa y civil. Se declara, por un lado, "verdadero Católico Apostólico Romano" y, por otro, asume que su condena "a último suplicio" ha sido justa y legal. Negarlo sería, incluso, contraproducente para conseguir sus objetivos, y su conformidad con la justicia republicana es utilizada por él como recurso retórico de llamado de atención, que se ve reforzado gráficamente por una triple interrogación: "¿¿¿¿os puedo hablar con mayor sinceridad???”.

Almeida ha sido condenado a pena de muerte por el asesinato del cura de Machetá, Francisco Tomás Barreto, cometido, así lo describe el mismo escrito, "con execrable alevosía e inaudita crueldad", en la noche del 28 de mayo de 1828. Pero

5. Ver Ortiz-Hernández (2016). 
él, después de aceptar una justa sentencia, en su descargo culpabiliza a otros como los autores del asesinato, cuyas originales intenciones, dice, no eran las criminales: "jamás creí que se iba a cometer este crimen atroz y sacrílego; nunca, nunca invité a sus autores; ni siquiera me pasó por la imaginación cooperar a tan enorme y abominable atentado contra un Sacerdote de nuestra Sacrosanta Religión".

Niega su implicación en el crimen y niega, inmediatamente, su implicación en las motivaciones iniciales que lo causan: el robo de los bienes de Francisco Tomás Barreto. Ni un delito ni otro dice haber cometido, y sus preocupaciones parecen estar dirigidas hacia el sentido personal de la honra. Va a ser sentenciado públicamente ante los ciudadanos, ante sus compatriotas, y este es el hecho que realmente le incomoda: "Otros son los delitos que confío purgar con el sacrificio de mi temprana vida en un patíbulo ignominioso ante el divino Juez de todos los hombres". Por ello, califica estos momentos carcelarios, previos a su pública muerte, como unos "terribles instantes". Por ello, trata a sus posibles lectores de "amados compatriotas" y les pide, con la intercesión de Cristo, su "natural compasión" para "su eterna felicidad" o salvación.

Ante el "infortunio" en el que se encuentra, pide perdón espiritual y toma su actuación como ejemplo contrario al que los colombianos, en una naciente nación y con sus "virtudes", deben seguir: "No os digo que me disculpéis; únicamente os ruego que seáis misericordiosos con mi pobre alma, y que condoliéndoos de mi lastimoso infortunio procuréis evitarlo haciendo brillar el teatro de las virtudes en nuestro preciosos suelo colombiano".

La Independencia no logró anular en su totalidad la legislación española en materia de derecho penal, y tanto la ley penal en los documentos constitucionales que van de 1810 a 1832, como en los códigos nacionales de 1837 y 189o, heredaron un conjunto de prácticas que se mantuvieron intactas hasta prácticamente la segunda mitad del siglo XIX, pues no es sino hasta 1934 que se promulga el primer código penitenciario colombiano. El amplio catálogo de derechos de las cartas constitucionales encontró su antítesis en los delitos tipificados por medio de leyes que exigieron fidelidad a la República mediante medidas represivas de las conductas contrarias a los intereses políticos en casos ejemplares como el hurto a la propiedad privada, la conspiración y la traición a la patria, la inspiración al "desaliento o espíritu rebelde" o la malversación de la hacienda pública. Las penas tendieron a intensificarse con el rigor de las leyes en la fundación de la República (Mayorga-Ulloa, 2015; Peñas-Felizzola, 2006:78-90).

La cárcel, en los primeros momentos republicanos, todavía se presentaba como un lugar de estancia provisional o de tránsito hacia la ejecución pública, si la sentencia de los reos lo dictaminaba. Como espacio físico, su organización, seguridad e higiene mantenía la naturaleza y los mecanismos de castigo y control social típicos 
de las sociedades del Antiguo Régimen, tales como las ejecuciones públicas ${ }^{6}$. Según el Código Penal español de 1822, que fue modelo, junto al francés de 1810, para confeccionar el colombiano de 1837 , al condenado a muerte se le debía notificar su última sentencia 48 horas antes de su ejecución, y durante ese periodo se le debían proporcionar "todos los auxilios y consuelos espirituales y corporales que apetezca". Durante su camino al patíbulo, cada doscientos a trescientos pasos, el pregonero debía publicar en alta voz el nombre del condenado, su delito y la pena impuesta7.

A mitad del siglo XVIII, en un caso descrito por María Carbajo (2007), que se dio en la ciudad de Madrid (España), el reo abandonaba su celda de la cárcel, "entraba en capilla" y dos días antes, normalmente, se le comunicaba el momento de la ejecución. En la capilla comían, dormían y rezaban ante un pequeño altar alumbrado con velas. Una disposición real de 1755 adoptó la medida de mantener en lo sucesivo estancias separadas para los reos que pudieran coincidir en la cárcel y la prohibición del acceso a la capilla de quienes solo por curiosidad solicitaban ver a los condenados. Una vez que el reo estaba en capilla, su alma era objeto de atención por los capellanes y religiosos que los atendían, procurando por la salvación de su alma a través del arrepentimiento de sus pecados en la confesión (Carbajo-Isla, 2007: 82-83).

Otra carta de despedida, esta vez firmada por Manuel Anguiano, dirigida a su madre Rosalía Guillin, y fechada, en la cárcel de Bogotá, el 18 de diciembre de 1833, hace explícita la situación del reo, encontrándose en capilla y confesado cuando la carta se redacta, un día antes de ser ejecutado: "Mi querida mamá de todo mi corazon, desde mi capilla le dirijo ésta dándole el último à Dios para siempre; mañana à las nueve i media de la mañana voy à morir afrentosamente en un patíbulo en la plaza pública de esta ciudad; pero me queda el consuelo de que estoy bien confesado, y moriré como buen cristiano" (Para los granadinos. Carta del desgraciado jóven cartajinés Manuel Anguiano, 1833) ${ }^{8}$.

6. Ver Aguirre (2009: 209-252).

7. Artículos 31, 32 y 42 (Código penal español..., 1822).

8. Este tipo de cartas en concreto, al igual que las muestras citadas, podemos adscribirlo al género de la "literatura de patíbulo", pero hay que considerarlas como cartas públicas con sentido político, que utilizan un lenguaje distinto al de las cartas y sentencias motivadas por la violencia o la delincuencia común; lenguaje que es el que aquí nos interesa y luego analizamos. Las conspiraciones políticas en la primera mitad del siglo XIX se sucedieron con frecuencia, y el caso del teniente de caballería Manuel Anguiano, tachado de "agente de Bolívar" bajo la presidencia de Francisco de Paula Santander, es uno de ellos, pues fue partícipe de la llamada Conspiración de Sardá, cuyos principales gestores fueron el general español José Sardá, el coronel Mariano París, y José María Serna (Santos-Molano, 2011: 123-150). Las cartas de despedida de los reos políticos sentenciados a muerte por conspiración se reprodujeron en la imprenta, y a ellas, desde facciones políticas contrarias, se podía responder con rapidez. La carta de Manuel Anguiano, hijo adoptivo del general Sardá, es respondida al día siguiente por "unos militares 
El escrito de Almeida es, esencialmente, una confesión, y esto lleva a pensar en la carta como una "escritura del yo", una escritura sobre sí mediante la cual se dirige la mirada hacia el interior de uno mismo como objeto de conocimiento. Desde esta mirada que nos envuelve, nos subjetivamos, establecemos relaciones con nosotros mismos. Pero la carta suele tener un receptor distinto al yo, un receptor que puede actuar como confesor; desde este punto de vista, sería entonces la mutua relación emisor-receptor o las expectativas de nuestros deseos ante la recepción ajena las que van formando el cuidado de sí. La carta, como "tecnología del yo", según Michel Foucault (1995), permite a los individuos efectuar, por cuenta propia o con la ayuda o atención de otros, cierto número de operaciones sobre su interior (pensamientos, conducta) o sobre su forma de ser, obteniendo así la posibilidad de transformarse a sí mismo con el fin de alcanzar felicidad, pureza, sabiduría, inmortalidad, salvación. En la carta de Almeida, sin consideraciones sobre la "verdad", se representan sentimientos, pensamientos, deseos, impulsos ("Estos son los sentimientos de vuestro ciudadano infeliz") que llevan a buscar dentro de sí, mediante un ejercicio de reflexión, por breve que este haya sido, los sentimientos ocultos. La carta es la transcripción de un estado de conciencia que enfatiza lo que se ha hecho9.

El cristianismo es una religión de salvación y confesional, debe conducir al individuo de una realidad a otra, de la vida a la muerte y, con ella, a la eternidad. Por medio de la confesión, las personas intentan saber qué es lo que está pasando en su interior, deben admitir sus faltas, reconocer las tentaciones, los deseos, y cada cual está obligado a revelar estos "sentimientos", bien a Dios, bien a la comunidad, con lo que se estaría admitiendo el testimonio público o privado sobre sí. Los sacramen-

que no capitulan con los enemigos", diciendo de ella que "está desfigurada, i que se ha publicado para alarmar à los incautos, i concitar animosidades i odios" (Para los granadino, i no granadinos 1833 ). Con abundancia de detalles, en notas a pie de página, la misma carta de Anguiano se vuelve a responder a comienzos de 1834, en la imprenta de Cartagena, de Manuel María Guerrero. Después de su significativo título, se citan las causas por las que la carta se reimprime, añadiendo aclaraciones en favor del régimen imperante: "Reimprimimos la carta siguiente para que circule como debe circular, es decir con las notas y aclaraciones del caso, porque lo estudioso de ella y el modo misterioso con que la hemos recibido, nos ha hecho emprender este trabajo en obsequio de la justica y de la sana razón. Vea pues el público y deduzca" (Sutilizas y arterías..., 1834. Sobre el fusilamiento público por los españoles el 2 de marzo de 1815, en la plaza de Cartagena, del padre de Manuel Anguiano, llamado de la misma manera, antiguo coronel de ingenieros del Ejército español y general de brigada e inspector de los cuerpos facultativos durante los movimientos independentistas, ver Urueta (1886).

9. El recurso a la imprenta para hacer una confesión pública reforzaba el estatuto de verdad con el que se quería dar a conocer la última palabra del reo. José Raimundo Russi (1851) hace publicar el texto titulado Alpúblico sensato: a los nobles republicanos; a los hombresque tengan corazón i honor. En él, se declara inocente del homicidio por el que se le acusa y en el momento en que lo hace ("que soi perfectamente inocente”) señala "que la imprenta es la cátedra de la verdad” (Alpúblico sensato..., 1851). 
tos de penitencia y confesión de los pecados son una forma de descifrar la verdad acerca de sí, de indagarse. Una de las principales formas de revelación, dice Foucault (1995), sería la exomologesis o "reconocimiento del hecho", un reconocimiento de sí mismo como pecador y penitente, que sería un reconocimiento dramático del estatuto propio del penitente que, haciendo pública su confesión, podía borrar el pecado y restaurar la pureza que había adquirido por el bautismo.

Los reos se confiesan, ante el capellán de la cárcel, poco antes de morir y, además, mediante la redacción del impreso que otros, como autores del mismo, han elaborado, hacen pública su confesión. Es, por tanto, un doble ejercicio confesional que encuentra en el hecho religioso su principal motivación. En el acto de penitencia, además, aunque generalmente sí se declaraban culpables, no se tenía que detallar la verdad, sino mostrarse a sí mismos como pecadores para, al mismo tiempo, romper con su pasado. La penitencia era una forma de mostrar que se era capaz de renunciar a la vida y a sí mismo, de enfrentarse a la muerte y aceptarla.

La carta-despedida de los reos representa la verbalización y la fijación por escrito de los pensamientos. En la argumentación de Foucault, esto podríamos tomarlo como otra de las formas de revelación de sí mismo, lo que se ha llamado en la literatura espiritual "exagoreusis", una forma de verbalizar los pensamientos que, sin ser guiada aquí por una relación de obediencia hacia otro como maestro, sí es dirigida, en su justa proporcionalidad, por los intereses de quien escribe la carta, quien debe obtener información del reo al menos de tres aspectos comunes que aparecen en este tipo de literatura de patíbulo: su entorno familiar, el desarrollo del hecho criminal y su adscripción política (Foucault, 1995: 48, 80-81) ${ }^{10}$.

\section{La sentencia que condena a José de Almeida}

Los "romances de reos" o "romances de ajusticiados" de la literatura de cordel española podían ser elaborados a partir de diversas fuentes informativas: orales, periodísticas, judiciales. Recordemos que la Hermandad de Ciegos de Madrid obtuvo, en 1748, por decreto del Consejo de Castilla, privilegio para confeccionar las "relaciones de los Reos ajusticiados en esta Corte para el socorro de los pobres

10. Hay que decir, al mencionar a Foucault, que no es el interés aquí presentar un análisis conceptual del poder inscrito esencialmente sobre la noción de disciplina (como hace en Vigilar y castigar. El nacimiento de la prisión); estaríamos, más bien, cercanos a la fórmula, aunque también debida a Foucault, de Michel de Certeau (1996: 152-162), por la cual la escritura de la ley y del derecho se inscribe sobre los cuerpos. La imprenta representa la articulación del texto legislativo sobre el cuerpo por medio de la escritura y el suplicio, así como la literatura que lo rodea, es una demostración simbólica del poder de los Estados a fin de inspirar miedo y respeto, y mantener los cuerpos, por medio de códigos, dentro de una norma. 
ciegos" (Botrel, 1993:50). El procedimiento era el siguiente: la Hermandad se informaba de que ya había salido el anuncio para ajusticiar al reo que estaba en la Real Cárcel de la villa de Madrid; por orden de la Sala de Alcaldes, obtenía del Relator de la causa un extracto de la misma y, a partir de ella, hacía o mandaba a hacer una relación de sus delitos, para que con su venta "[sirviera] de universal escarmiento" (Botrel, 1993: 50). Se trataba de textos que seguían un esquema narrativo similar y daban a conocer crímenes, describían a sus criminales y relataban el castigo que estos recibían ante el cadalso.

Del caso de José Manuel Almeida desconocemos si hubo una composición poética. A la confesión anterior o carta-despedida del propio reo, sí podemos añadirle el "sumario" del caso, que se hizo público en el Suplemento a la Gaceta de Colombia, $\mathrm{n}^{\mathrm{o}} 355$, del 29 de junio de 1828 (Sentencia pronunciada..., 1828) ${ }^{11}$. Está encabezado por el título de "Sentencia", pero realmente, como dice el propio escrito, donde en su final remite a la "sentencia consultada", se trataba del sumario, o sea, del conjunto de actuaciones dirigidas a preparar el juicio criminal, haciendo constar la perpetración de los delitos con las circunstancias que podían influir en su calificación para determinar la culpabilidad y prevenir el castigo de los delincuentes. Las sentencias, en especial de última instancia, tienen como naturaleza que no entran a discutir sobre los asuntos de fondo o de forma; solo confirman o niegan los autos previos que se supone han recogido los elementos de la discusión. Se basan en textos que ordenan los tribunales: se llaman sumarios y reemplazan a los expedientes completos que se podían perder cuando transitaban de una jurisdicción a otra. Solamente la jurisprudencia es la que profundiza en alguno de esos aspectos, pero no siempre. Es por ello que las sentencias son generalmente pobres en información.

Estos textos, directamente relacionados con el crimen, se vieron rodeados de un tipo de literatura costumbrista, como las obras de José María Cordovez Moure (1955) o de Daniel Florencio O'Leary (1879-1888), que podían recrear algunos sonados hechos entre la población colombiana de la época. Una variedad de escritos que podían incluir recursos ficcionales, se articulaban al espectáculo público del patíbulo y nos permiten aproximarnos a una concreta cultura política y jurídica, a la caracterización del crimen y sus criminales, y al mensaje moral que, sobre todo con la publicación de la sentencia, se pretendía difundir.

La sentencia definitiva fue dada por la Corte Superior Departamental de Cundinamarca y Boyacá, con sede en Bogotá, el 18 de junio de 1828. El 24 de junio, se fecha en Bogotá la carta impresa de José María Almeida. De un día después, el 25 de junio, es el resumen o sumario de la sentencia, que se publica, como señalamos, en

11. Ver Colección de documentos relativos a la vida pública del Libertador de Colombia y del Perú Simón Bolívar. Para servir a la historia de la independencia del Suramérica [Tomo XV] (1828: 127-132). 
la Gaceta de Colombia, órgano oficial del Gobierno republicano, el 29 de junio. Dos días antes, se había ejecutado la sentencia que condenó a Manuel Almeida, Pioquinto Camacho, Dolores Pinto, Pedro José Amaranto y Manuel Vega, por el "asesinato alevoso" ejecutado en la persona del presbítero Francisco Tomás Barreto, párroco de Machetá, en su casa de Bogotá, la noche del 28 de mayo, por robarlo.

Además de otros fundamentos jurídicos que argumentan el dictamen de la sentencia, esta sigue formalmente la "Ley sobre procedimiento en las causas de hurto y robo", del 3 de mayo de 1826. Esta ley, según Gilberto Enrique Para, estableció la cooperación entre el poder político y el judicial, promoviendo la ayuda entre gobernadores, y jueces letrados y de hacienda para las averiguaciones criminales y las capturas de los sospechosos. Ocurrido el delito, los jueces debían buscar inmediatamente las pruebas necesarias para esclarecerlo en el domicilio donde había ocurrido, incluso en ausencia de los procuradores (abogados defensores) o del escribano, para lo cual se podía recurrir a ciudadanos que supieran leer y escribirir ${ }^{12}$.

Desde que ocurrieron los hechos hasta la emisión de la sentencia, solo habían transcurrido veinte días. La ley mencionada suprimía los tiempos y requerimientos de la antigua ley colonial y así, por ejemplo, el juez estaba autorizado a eliminar la declaración escrita de los testigos para agilizar el proceso. Bastaba con lo visto y oído de las personas cuyos testimonios constituían las pruebas. Junto a las pruebas materiales, el juez, no obstante, debía atender las pruebas testimoniales y la ley, en este sentido, mantenía las distinciones personales de un testigo como determinantes de la verdad judicial. El sistema judicial colombiano comenzó a consolidarse legalmente con la ley orgánica de tribunales de república, expedida el 11 de mayo de 1825. La lentitud era una de las principales características con las que se percibía la justicia colonial, pero las medidas republicanas encaminadas a agilizar el sistema no lo consiguieron; al contrario, las causas irresueltas aumentaron, y la Independencia experimentó un aumento de delitos contra la propiedad y las personas. Las crónicas de Cordovez Moure en el diario El Telegrama, de fines del siglo XIX y principios del $\mathrm{XX}$, y la amplia discusión pública que en la época se dio sobre la pena de muerte, unos a favor de ella, otros en contra, son buenas muestras de ello.

La sentencia condenatoria de Almeida parece recorrer con cumplimiento exacto el articulado de esta ley de hurto y robo, y deja ver la influencia que las leyes republicanas seguían manteniendo del antiguo régimen colonial. Si bien existió en España una corriente humanista e ilustrada de los teóricos del derecho penal, como Manuel de Lardizábal y Uribe (abogado de origen mexicano que, a iniciativa de Carlos III, elaboró el Discurso sobre las penas para preparar la redacción de una codificación

12. Sobre estas observaciones de la ley de hurto y robo, y las concepciones teóricas de la ley penal, ver Parada-García (2014: 68-76, 99). 
penal), estos no abandonaron la defensa del absolutismo y la fe. La noción de la pena en la teoría del derecho español suponía una autoridad suprema, que en el Discurso de Lardizábal se equiparaba con Dios, sin negar, no obstante, la posibilidad de un pacto social que permitiera a los hombres ser gobernados por el soberano o que este recibiera de Dios el poder de gobernar.

El jurista español José Marcos Gutiérrez, a quien se hace mención indirecta en la sentencia con uno de sus textos (Compendio de las variadas resoluciones de Antonio Gómez), en su Práctica criminal de España, concibe así la idea de Lardizábal: “[los criminales] serán infames toda su vida para todos los efectos civiles como enemigos de la patria y destructores del pacto de la sociedad que une a todos los pueblos y vasallos con la Cabeza Suprema del Estado" (Gutiérrez, como se citó en Parada-García, 2014: 75). Este es el espíritu que condena a sufrir una pena ejemplar de último suplicio a los cinco reos. La sentencia se fundamentaba en la ley de hurto y robo, de 3 de mayo de 1826; en la Nueva Recopilación de Castilla (1567); en las Siete Partidas (1265), y en el "Libro del Génesis, cap. 40, vers. 19", y obligaba a que la pena se ejecutara "en un día de concurso en la plaza mayor" de Bogotá13. La pena buscaba intimidar a los individuos y generar miedo colectivo, arrastrando a los criminales...

(...) en serones por bestias de alvarda hasta el lugar del suplicio, pregonándose el delito en las 4 esquinas; que por falta de verdugo sean fusilados en banquillos que se pondrán al pié de la horca; que despues de la ejecucion sean suspendidos en ella sus cadáveres, y permanezcan allí por cuatro horas; que cortándolos las cabezas á Almeida y á Camacho, se pongan en escárpias en las entradas públicas de esta ciudad; y que igualmente las manos derechas de estos, se pongan en los lugares, y con las inscripciones que expresa la sentencia consultada. (Sentencia, 29 de junio de 1828)

La aplicación de esta tradición jurídica señalada es constatable antes de instaurarse el régimen republicano. Hay ejemplos conocidos que utilizan un similar lenguaje "tremendista" con la pretensión de causar de inmediato un impacto en los afectos. Uno de ellos es el crimen pasional que cometieron, en 1770, en la ciudad de Popayán, los amantes Pedro García de Lemos y Dionisia Mosquera contra el marido de esta, Pedro López Crespo. El proceso judicial condenó a la "pena ordinaria de muerte" a don Pedro García de Lemos, a doña Dionisia Mosquera, mujer que fue de

13. La ley de Procedimiento Civil, del 13 de mayo de 1825, estableció para los Tribunales de la República civiles y criminales el siguiente orden de prelación de fuentes: $1 .{ }^{\circ}$ las leyes decretadas en lo sucesivo por el poder legislativo; $2 .^{\circ}$ las pragmáticas, cédulas, órdenes, decretos y ordenanzas del gobierno español dictadas hasta el 18 de marzo de $1808 ; 3 .{ }^{\circ}$ las leyes de la Recopilación de Indias; $4{ }^{\circ}$ las leyes de la Nueva Recopilación de Castilla, y 5. ${ }^{\circ}$ las Siete Partidas. 
don Pedro Crespo, a Joaquín Perdomo, a Pedro Luis de Borja, y a Francisco Fuche. Se debía ejecutar de la manera siguiente:

Don Pedro Lemus y Doña Dionicia Mosquera, serán condusidos al cadalzo publico donde sentados y arrimados a un garrote se les ahogará con un cordel, hasta que naturalmente mueran: Joachin Perdomo, Pedro Luiz de Borxa y Francisco Fuche se sacarán amarrados a la cola de un caballo, y serán conducidos por las calles publicas hasta el lugar de la horca, donde serán colgados del pescuezo, hasta que mueran, manteniéndolos en ella bastante tiempo con correspondiente guardia; y puestos después los cuerpos en el suelo, seran trozados y desqueartizados, cuyas cabesas en jaulas de fierro se clavarán en las puertas de la cárcel y los demás quartos, seran puestos bigas altas, repartidos por los caminos del Patía. (ACC, La Audiencia de Quito contra Doña Dionisia Mosquera y otros, Sección Colonia, Fondo Judicial (Col. JI-2cr.), fol. 2v.-3r.) ${ }^{14}$

Al castigo corporal, se sumaban la confiscación de la "mitad de los bienes de Almeida”, por un valor de 600 sueldos prevenidos por la ley, y el pago de los costos del proceso, que corrían "mancomunadamente con los otros reos, aplicados aquellos a penas de cámara". El castigo, efectivamente, se llevó a cabo. La correspondencia del canónigo Nicolás Cuervo y Rojas a su sobrino Rufino Cuervo Barreto, quien fuera vicepresidente de la República durante la presidencia de Tomás Cipriano de Mosquera y padre de los hermanos Rufino José y Ángel Cuervo, nos habla de este castigo. Como "asesinos sacrílegos”, fueron absueltos eclesiásticamente en el atrio de la Iglesia de San Carlos, y el mismo día, el 27 de junio, "se les llevó al suplicio arrastrados sobre serones por bestias de albarda en torno de la plaza mayor y pregonándose el delito en cada esquina”. Fueron colgados en la horca por cuatro horas y la cabeza de Almeida fue expuesta en San Victorino; la de Camacho, en Las Nieves; y las manos derechas de los mismos, en la casa donde se perpetuó el crimen (Díaz-Díaz, 1962: 272-273).

La literatura de José María Cordovez Moure (1955: 75) añade un simbolismo ficcional al acto, que es válido en tanto, nos dice el propio cronista, fue el primer crimen que escandalizó a la sociedad colombiana de la época. La ejecución tuvo lugar al frente de la cárcel, situada en el lugar del gran patio del Capitolio. A Almeida se le fusiló después de degradarlo. Al resto se les ahorcó "sacándolos a todos de la cárcel, arrastrados sobre un cuero de res en que había un gallo como emblema de ferocidad,

14. Los amantes escaparon a la condena y solo los esclavos cómplices fueron ajusticiados (Pérez-Silva, 1997). Ver también la sentencia que condenó, en enero de 1782, al líder de la revolución comunera que se dio en la ciudad colombiana de Socorro (Santander), José Antonio Galán (Arciniegas, 1986: 72). 
una culebra que representaba la alevosía, y un sapo para expresar la premeditación y frialdad en la comisión del delito" ${ }^{15}$.

El homicidio, de acuerdo a valoraciones de la moral cristiana, imponía determinados castigos que se aplicaban en el cuerpo del delincuente, pues la ideología de los teólogos consideraba al cuerpo como un objeto. El alma representaba al sujeto y, por ello, el castigo pretendía librar al alma para salvarla. Los castigos más frecuentes fueron las penas corporales, la confiscación de bienes, el destierro, la privación de la libertad, la infamia, la desmembración y la muerte. De esta manera, podemos entender el castigo "como una extensión de elemental venganza que se proyecta en la lesión de la misma clase de bien jurídico que el criminal había trasgredido" (Parada-García, 2014: 64).

Después de leer el contenido de la pena, el sumario previene que "se impriman y circulen las sentencias y la vista del señor fiscal”. La impresión tiene una función ejemplarizante ante los ciudadanos. La pena, más allá de su escabroso contenido, utiliza un lenguaje apropiado para las descripciones morales, el mismo lenguaje "tremendista" y morboso que se había empleado a lo largo de toda la sentencia, y cuya finalidad tiene que ver con la restauración de las conductas. Es este lenguaje el que nos permite comparar la sentencia con el estilo y las intenciones moralizantes de los romances de crímenes españoles, porque las intenciones son similares.

\section{El lenguaje jurídico-moral y la restauración de las conductas}

Sin detenernos, como dijimos, en las cartas de despedida ni en las sentencias motivadas por hechos estrictamente políticos, la sentencia de Almeida, que se hace pública con un propósito correctivo y utilitarista, despliega expresiones que acrecientan la atracción hacia acontecimientos desagradables para luego, como en un acto de pedagogía moral, repudiarlos: "cadáver con cinco puñaladas", "sacrílego alevoso

15. Rufino Gutiérrez (1920: 126-127), en sus Monografías, señala la relación que encontró en uno de los libros del despacho parroquial de Engativá, hecha por el doctor Saiz, cura de ese pueblo: "El 27 de junio [de 1828] se ejecutó la sentencia en Almeyda, Camacho, Vega y Amaranto, concebida en estos términos: fueron sacados de la cárcel grande, arrastrados en esteras a la cola de un caballo, pregonado su delito y sentencia en las cuatro esquinas, y luego conducidos a los banquillos, que estaban debajo de las horcas, y en ellas colgados los puñales del asesinato; fueron fusilados y después colgados de las horcas por tres horas, y descuartizados los principales autores, Almeyda y Camacho. Las manos de éstos fueron puestas frente a la casa de Barreto en escarpias y con sus inscripciones. La cabeza del primero está en San Victorino y la del segundo en San Diego, en el camino real (...). El día 2 de septiembre de 1828 fue ejecutada la sentencia de muerte de Dolores Pinto, en los mismos términos en que la sufrieron sus cómplices". 
asesinato", "puñaleta con que se ejecutó el homicidio", "fue con un rejo de enlazar", "con el mismo rejo escondido bajo las matas de la huerta y todo ensangrentado", "una gran malicia y depravación", "asesinato (...) atroz, alevoso (...) y escandaloso por ser ejecutado en la persona de un sacerdote, entrando a su casa de noche, con armas, palos y rejo, en número de cinc o personas con la mayor violencia" (Sentencia..., 1828).

La literatura "popularizada", de origen estrictamente popular o, si se quiere, folklórico, se mueve por coordenadas de interés distintas o desfasadas, no ajustadas, a la literatura culta: es otra literatura. Los autores y lectores o consumidores, en general, de la literatura popular tienden a valorar efectos exagerados, como la violencia extrema (Marco, 1977:49). El tremendismo se ha identificado con hechos truculentos de los que brota la muerte, sucesos que por su naturaleza causan horror y espanto. En la sentencia, los argumentos jurídicos que fundamentaban la pena y el sensacionalismo son los ejes sobre los que giraba la narración judicial. La cantidad de delincuentes sentenciados a tal muerte cruel (cinco) y las armas utilizadas (la puñaleta y el rejo) ya son dos notas de por sí escabrosas.

La ley de hurto de 1826 insistía, en su articulado, en dejar "razón circunstanciada" de las "armas" e "instrumentos" que hayan utilizado los delincuentes (Art. 5); en el juicio de los peritos sobre "señales, armas o cosas que hayan reconocido" (Art. 6); en la función del juez o alcalde de recoger las armas que sirvan de averiguación del caso (Art. 7), y, finalmente, como en la sentencia se muestra, en que quienes cometan un robo haciendo uso de armas sufrirán la pena de muerte (Art. 27).

Siguiendo el tufo de emociones fuertes que va dejando la descripción del crimen, y fundiendo el uso de las armas utilizadas en el mismo (puñaleta y rejo), similares en su simbolismo al del "cuchillo", reproducimos las consideraciones oportunas de Norbert Elias (1997: 164-165):

Según la forma de su utilización social, también el cuchillo es una encarnación del "espíritu" social, del cambio en los impulsos y deseos; es materialización de situaciones sociales y de leyes estructurales de la sociedad (...). Sin duda que el cuchillo es un instrumento peligroso en un sentido que podemos llamar racional: es un arma ofensiva; produce heridas y despedaza a los animales muertos. Pero esa peligrosidad evidente está rodeada de emociones. El cuchillo se convierte en el símbolo de las más diversas sensaciones que dependen de su objetivo y de su configuración, pero que no dimanan de forma racional de ese objetivo. El miedo que el cuchillo suscita supera al temor racionalmente justificado y es mayor que el peligro verosímil y "calculable” (...). El miedo, la repugnancia, la culpa, las asociaciones y emociones de todo tipo superan con mucho el peligro verosímil. Esto es precisamente lo que da a estas prohibiciones su especial solidez psíquica; esto es lo que les da su carácter de tabú. 
El “cuchillo", el "puñal” o la "puñaleta” son armas utilizadas con frecuencia en las crónicas de Cordovez como recurso simbólico que concede a su literatura esa "solidez psíquica" que la envuelve de fuertes emociones, e intenta así atrapar morbosamente a sus lectores. El cuchillo, por otra parte, como la navaja, en su doble uso de arma y herramienta útil para el laboreo o el momento de las comidas, fue un instrumento popular en la época, y se solía esconder o guardar en el chaleco o la faltriquera. El uso y abuso de armas blancas fue siempre un hábito en las provincias españolas, y las Pragmáticas reales, que alcanzaban a todo el territorio bajo dominio hispano, a partir de mediados del siglo XVIII y principios del XIX, repetían la prohibición de, además de pistolas, "trabucos, puñales, guiferos, almaradas, navaja de muelle con golpe o verola, daga sola, de punta chica o grande, de cocina o de faltriquera" (Lapeskera, 1995: 12) ${ }^{16}$.

Enlasnarracionesdesucesoscriminalesespañoles, comoenlascrónicas de Cordovez ("un gran cuchillo cabiblanco", "le pusieron un puñal al pecho", "apoyándole sobre el pecho la punta de un puñal") era frecuente la aparición repetitiva del arma blanca. Una muestra fiel la podemos encontrar en el apartado de romances de "Crímenes y sucesos nefandos", del Romancero general de La Rioja (España), donde aparece también el "cuchillo con que a su padre ha matado" (Villavelayo, El parricida y No me entierren en sagrado); "el puñal que la mató” (Logroño, Parricida castigado); "este grueso puñal" para dar "muerte fatal" (Cornago, Parricida venga el honor de su hermana); "un puñal de oro" con el que "le ha dao tres puñaladas" (Bañares, Un desdén castigado); o el "puñal” que con "tres puñalás", un "caballero" criminal mata a una niña en el romance Asturiana asesinada por un galán desdeñado que se recoge en la población de Aguilar del Río Alhama (Asensio-García, 1999: 680-703).

Estilísticamente, en La muerte a cuchillo, un "romance de crímenes" de la literatura de cordel española que nos sirve ahora de ejemplo, la válvula creadora del tremendismo se reduce a la desorbitación de los efectos: la muerte a cuchillo, horroroso y sangriento drama, temblad, la narración más tremenda, hombre semifiera, sangrienta escena, monstruo de Ciriaco, trabucazo, quince cuchilladas, arma mortífera, con mucha furia y violencia ${ }^{17}$. De esta manera se mostraba, haciendo concesiones al público e incluso siendo serviles con él, una concepción del mundo basada en "las frustraciones y negatividades que son propias del tremendismo, (...) [una] incapacidad para la abstracción (...); en el mundo de lo degradado, incluso de

16. Las Cortes de 1828 criticarían la "multiplicación de homicidios, debidos sin duda a la desmoralización general y de cierta ferocidad en las costumbres" que se ponían en relación con "la invasión napoleónica de 1808", que hizo común el uso de armas blancas, y "el sistema constitucional del Trienio". Las Cortes hablaban de "frecuencia de asesinatos, homicidios alevosos y otros crímenes semejantes" (Lapeskera, 1995: 13). 17. Sobre estos rasgos del "tremendismo" que se comentan aquí, ver Rubio (2018: 62-65). 
lo abyecto (...), [un] refugio del autor incapaz de crear una obra literaria" (López Molina, como se citó en García de Enterría, 1973: 194).

Frente a esta que podríamos llamar "baja calidad literaria" (que utiliza el tremendismo para exagerar los efectos), las cartas de despedida de los reos, los relatos periodísticos y costumbristas de autores como José María Cordovez y Pedro María Ibáñez, así como los sumarios públicos de las sentencias colombianas, textos todos que giraron alrededor del patíbulo, sí recurrieron a un estilo literario capaz de mantener un emotivo tono ${ }^{18}$. La descripción de las emociones, sea el caso de las despedidas, se envolvía frecuentemente de un lenguaje poético culto; y las crónicas recurrieron a las complejas técnicas del suspenso y el misterio. Pero ambos tipos de literatura, la romancística y esta otra que surgió alrededor del patíbulo, sí participaron de unos orígenes comunes y de un gusto sensacionalista y popular: "Los crimenes de don Chepe Cordovez, voceaban por las calles los chinos para vender los ejemplares del Telegrama donde aparecían los solicitados folletines" (Díaz-Díaz, 1962: 271).

Con una alta capacidad para conmover, los textos de las penas que publicitaban las sentencias ya eran de por sí un material que fácilmente podía ficcionarse, como hemos visto, pero su propio vocabulario y la forma de ejecutar al condenado conllevaban, intrínsecamente, notas de sensacionalismo y emociones fuertes cercanas a los efectos pretendidos, no a su estilo, del tremendismo: "que (...) sean suspendidos en ella sus cadáveres (...) que cortándoles las cabezas (...) se pongan en escarpias (...) y que (...) las manos derechas (...) se pongan en los lugares y con las inscripciones que expresa la sentencia"19.

La variedad de escritos que originó el patíbulo reutiliza tradiciones discursivas europeas cuya función es la de producir modelos de aprehensión de lo social. A pesar de sus aparentes diferencias ideológicas con la noticia política de prensa, el sermón cívico o el discurso militante, estos textos, enmarcados en un proyecto liberal de modernidad como el que representan las independencias latinoamericanas, recurren a unas mismas fórmulas retóricas que, investidas de autoridad y no exentas de dramatismo al describir situaciones conflictivas, resaltan las emociones respecto a la función del Estado y sus nuevas instituciones, que deben garantizar una identidad colectiva que solo se logra con el respeto a la ley, un respeto muchas veces reclamado, desde la autoridad gubernamental, por quienes se oponían a las

18. Las Crónicas de Bogotá, escritas por Pedro María Ibáñez, se publicaron en cuatro volúmenes que aparecieron en los años 1913, 1915, 1917 y, póstumamente, en 1923. Una antología de sus Crónicas puede verse en Ibáñez (2014).

19. Sobre uso de recursos propios del género romancístico, emparentados con lo que se ha llamado una "literatura performancial", cercana a lo "esperpéntico", para crear sensaciones proclives a la desmesura y al patetismo, ver Díaz-Viana (1988: 28-36). 
cartas de despedida públicas que hacían los reos políticos sentenciados por sedición contra el Gobierno de turno: "De lo contrario siempre se verán erizadas de patíbulos las plazas públicas, porque no es posible que los tribunales ni el gobierno dejen de aplicar la ley al delincuente, al que hoyando todo lo más sagrado que hay en el mundo, quiera mantener el país en agitaciones y en desórdenes perdurables” (Sutilizas y arterías..., 1834).

El dramatismo que representa la ejecución del reo, reflejada retóricamente en sus cartas de despedida y en las sentencias de sus juicios, forma parte de una cultura letrada (literaria, judicial) que legitima el contexto político dominante extremando las convicciones y pasiones religiosas. La tensión dramática, propia de la "retórica del exceso", cuya estética destaca los sentimientos humanos y sus contradicciones, posee eficacia persuasiva y activa los afectos ${ }^{20}$. Arrastrar al reo en serones por bestias de albarda, fusilarlo, suspender su cadáver de la horca durante cuatro horas, cortarle luego la cabeza y las manos para ponerlas con escarpias en las entradas públicas de la ciudad de Bogotá son manifestaciones de un ensañamiento con el que se mantiene una tradición y, al mismo tiempo, se pretende consolidar el "horror social" que produce el aplicar una irracional relación entre la dimensión del delito y la pena ejecutada (Rodríguez-Sánchez, 1994: 29).

La lectura está investida de un poder de persuasión que es capaz de transformar a los lectores y de hacer que sean como los textos pretenden, o al menos se cree que estos tienen la capacidad de modelar los modos de ser. El conjunto de recursos estilísticos, además de poder ponerlo en relación con una manera de hacer, como se ha dicho con frecuencia de los romances de crímenes, sobre todo de los escritos a fines del siglo XIX, llena de "incapacidades" frente a las demostraciones de la "cultura letrada", y hay que articularlo con una dimensión sociosimbólica en la que también se deben incluir a los variados géneros de la literatura de patíbulo. La prensa de la época representaba al homo criminalis, dicho en términos de la ciencia criminológica de entonces, como un sujeto que cometía un delito en sus diferentes grados y resultaba ser un "otro" que poseía una naturaleza diversa frente al "nosotros". El sentido moral era el que inspiraba el deber de hacer el bien y evitar el mal, y así su debilidad o ausencia constituiría una falta moral grave. ${ }^{21}$ Muchos de los romances de crímenes del siglo XIX y de las crónicas periodísticas sobre casos célebres se relacionaban con los documentos del proceso penal respectivo (visitas fiscales, defensas, sumarios o

20. Sobre este dramatismo con fines políticos en la producción textual, ver Lillo y Urbina (2010: 7-18).

21. Estas y las siguientes observaciones, para las que el autor utiliza como punto de partida las obras de Michel Foucault (Los anormales y La vida de los hombres infames), están tomadas del texto de Máximo Sozzo (2007: 23-65). 
sentencias judiciales) e incluían la descripción del sujeto procesado, en su aspecto y en sus rasgos biográficos, calificativos que intensificaban la "esencialización de la diferencia" como "homicida", "abyecto criminal", "feroz asesino", "salvaje", "monstruoso", "fiera".

Estos retratos, que emplean la misma terminología que encontramos en la sentencia de Almeida ("una gran malicia y depravación", "asesinato atroz, alevoso y escandaloso"), se enmarcan en un discurso que en esta época ya no es el "jurídico-biológico" del pasado, sino el "jurídico-moral" que tiene en cuenta la "monstruosidad de comportamientos" ubicada en el "dominio de la criminalidad". Evidentemente, el estilo cargado de intensos adjetivos que envuelve al sumario de la sentencia obedece a un relato ficcional. Se trata de crímenes de sangre, de delitos de máxima gravedad que se escenifican en el ámbito de las relaciones "más sagradas y naturales" como son, en este caso, los que atañen al ejercicio sacerdotal, y reciben la calificación de verdaderos "crímenes contra natura". Lo que convierte a los sentenciados en criminales dentro de la narrativa discursiva de la sentencia no es tanto la descripción de lo que son, sino, paradójicamente, de lo que hacen, de su comportamiento. Se trata, entonces, no de una caracterización biológica, sino moral, que pretende, dentro de una "potencialidad" existente en cada uno de nosotros de ser delincuentes, crear arquetipos para disuadirnos de convertirnos en el homo criminalis que encarnaba la demonización, la violencia y la atrocidad de conductas social e institucionalmente penalizadas.

Las sentencias y confesiones públicas de los reos no muestran las ejecuciones de la pena capital como un simple hecho noticiable, sino con perspectivas moralizadoras. El reo como sujeto no importa tanto como el hecho de su estancia en capellanía, su arrepentimiento y el impacto social que puede producir su "justa" muerte. Pero las pretensiones de la caracterización moral no solo se centran en los casos extremos de la criminalidad, también son un llamado de atención a restaurar conductas. La "conducta restaurada" (Schechner, 2011), expresada bajo esa potencialidad personal, es “'yo comportándome como si fuera alguien más' o 'como si fuera además de mí mismo', o 'como si no fuera yo mismo', como en el trance; pero este 'alguien más' podría también ser 'yo en otro estado de ser o existir', como si hubiera múltiples 'yo' en cada persona” (Schechner, 2011: 39). El ejemplo arquetípico que se construye a través del crimen cometido por José de Almeida y la difusión pública de su sentencia, mediante las reiteraciones o repeticiones de un determinado tipo de lenguaje, propias de la performance, mueve a los individuos y a la comunidad a la restauración de sus comportamientos. La "conducta restaurada" ofrece la posibilidad de volver a ser lo que alguna vez se fue o, con mayor frecuencia, de ser lo que nunca se fue, pero se deseó haber sido o llegar a ser. 


\section{Conclusiones}

El caso de José Manuel Almeida tuvo amplia repercusión en la opinión pública del momento y, junto a otros, todavía ocultos en nuestros archivos, demandan la atención de los investigadores para poder profundizar en el estudio de los géneros literarios que tuvieron su origen en el patíbulo. Aunque en Colombia no hubo una tradición romancística o coplera alrededor de quienes fueron ajusticiados por sus crímenes, como la hubo con profusión en España, sí se dio una tipología editorial que recogía las últimas palabras del condenado a manera de confesión pública. La voz del reo antes de ser ajusticiado, por medio de intermediarios expertos en la redacción de estas "confesiones" o "cartas de despedida", se hizo pública mediante la imprenta. El estudio de estas "cartas" requiere, en principio, una sistemática recopilación de los casos que se dieron durante el siglo XIX colombiano, y deben ser comprendidos en el contexto del ritual punitivo que implementó la república naciente en las ejecuciones públicas con fines moralizantes y que pretendían el apego al nuevo régimen y su justicia.

El patíbulo originó también una literatura costumbrista que recurrió a fuentes orales, periodísticas y judiciales para construir, esencialmente, "crónicas" que en unos momentos donde, al menos en la capital de Colombia, la criminalidad aumentó notablemente, fueron reclamadas por los lectores dedicados a su seguimiento. Las crónicas, así como, en menor medida, las confesiones de los reos, recurrieron a las sentencias que sobre los casos respectivos se hicieron públicas en la prensa. Esta variedad de escritos empleó unos recursos estilísticos y recurrió a unas técnicas de recogida de información para su producción que nos permiten compararlos con los romances de crímenes de la literatura de cordel española, para situar su particular narrativa dentro del discurso general jurídico-moral de la época, que pretendía ser un llamado de atención a restaurar conductas.

La cárcel sintetiza la política que el poder estatal establece en torno a la violencia programada para transmitir las imágenes del cambio de conductas en los delincuentes. Se trataba de mostrar, a través de distintos actores, situaciones y escenarios, donde también se integraron distintos géneros literarios, cómo se daba ese cambio en un sujeto que aceptaba el suplicio para legitimar su salvación ante los ojos de Dios y de un público profundamente religioso.

Este tipo de literatura marca la representación de una realidad donde se dan cita la desigualdad social, la violencia humana y la delincuencia organizada; muestra una relación de ejecuciones que sitúan a la pena de muerte como el final de una compleja violencia que el poder republicano administra a través de diversos escenarios y situaciones, y de diversas instancias implicadas, como la Iglesia y los aparatos 
policiales, judiciales y administrativos. El patíbulo, la muerte por ejecución, carecía de privacidad en el pasado y se convertía en un espectáculo público. Una vez que la sentencia se hacía firme, la ejecución era anunciada por medio de pregones, y numerosos cargos u oficios (jueces, escribanos, alguaciles, carceleros, religiosos, soldados, verdugos) se disponían a participar en ella ante un nutrido público. La solemnidad con que se revestía el momento cobraba así un carácter ejemplificador, contribuía a dar al acto un significado edificante y moralizador al mismo tiempo, que podía servir para dar apoyo espiritual al reo en los últimos momentos de su vida.

Estas mismas características fueron recursos empleados para poder redactar la última confesión de los reos, cuya edición o impresión podía ser vendida públicamente. Alrededor del patíbulo giraron aspectos ceremoniales que, desde una profunda cultura religiosa, el Estado colombiano utilizó para incidir en la opinión pública. Aspectos ceremoniales que alcanzaron a la cultura escrita, y ha sido desde ella, desde unas contadas muestras que estudios posteriores deben ampliar, que hemos intentado aproximarnos al contexto judicial del momento y a sus pretendidos efectos morales.

\section{Referencias}

\section{Fuentes primarias}

\section{Archivos}

Archivo Central del Cauca, Sección Colonia, Fondo Judicial.

\section{Documentos impresos y manuscritos}

A mis compatriotas [José Manuel Almeida] (1828). Bogotá: Imprenta de Bruno Espinosa. Sig.: Biblioteca Nacional de Colombia (BNC), Biblioteca Digital (BD), Fondo Anselmo Pineda (FAP).

Al público sensato; a los nobles republicanos, a los hombres que tengan corazón i honor [José Raimundo Russi] (1851). Bogotá: Imprenta de Morales i Compañía. Sig.: Biblioteca Nacional de Colombia (BNC), Biblioteca Digital (BD), Fondo Anselmo Pineda (FAP).

Código penal español, decretado por las Cortes en 8 de junio, sancionado por el Rey, y mandado promulgar en 9 de julio de 1822. (1822). Madrid: Imprenta Nacional.

Colección de documentos relativos a la vida pública del Libertador de Colombia y del Perú Simón Bolivar. Para servir a la historia de la independencia del Suramérica [Tomo XV] (1828). Caracas: Imprenta de G. F. Devisme. 
El ajusticiado a sus conciudadanos [Teodoro Rivas] (1846). Bogotá: Impreso por José Ayarza. Sig.: Biblioteca Nacional de Colombia (BNC), Biblioteca Digital (BD), Fondo Anselmo Pineda (FAP).

El interés patriótico [José Ayarza] (1833). Bogotá: Imprenta de Bruno Espinosa. Sig.: Biblioteca Nacional de Colombia (BNC), Biblioteca Digital (BD), Fondo Anselmo Pineda (FAP).

La última hora de un infeliz en capilla (1839). Bogotá: Impreso por José Ayarza. Sig.: Biblioteca Nacional de Colombia (BNC), Biblioteca Digital (BD), Fondo Anselmo Pineda (FAP).

Para los granadino, i no granadinos (1833). Bogotá: Imprenta de Nicomedes Lora. Sig.: Biblioteca Nacional de Colombia (BNC), Biblioteca Digital (BD), Fondo Anselmo Pineda (FAP).

Para los granadinos. Carta del desgraciadojóven cartajinés Manuel Anguiano [Manuel Anguiano] (1833). Bogotá: Imprenta de Nicomedes Lora. Sig.: Biblioteca Nacional de Colombia (BNC), Biblioteca Digital (BD), Fondo Anselmo Pineda (FAP).

Sentencia pronunciada contra los autores del asesinato alevoso ejecutado en la persona del presbitero Tomás Barreto (1828). Suplemento a la Gaceta de Colombia, 355.

Sutilizas y arterias de los enemigos del sosiego público (1834). Cartagena: Impreso por Manuel María Guerrero, 1834. Sig.: Biblioteca Nacional de Colombia (BNC), Biblioteca Digital (BD), Fondo Anselmo Pineda (FAP).

Triunfó la lei [Los patriotas comprometidos] (1835). Bogotá: Imprenta de Nocomedes Lora. Sig.: Biblioteca Nacional de Colombia (BNC), Biblioteca Digital (BD), Fondo Anselmo Pineda (FAP).

\section{Fuentes secundarias}

Aguirre, Carlos (2009). Cárcel y sociedad en América Latina: 1800-1940. En Historia social urbana. Espaciosy flujos (pp. 209-252), editado por Eduardo Kingman-Garcés. Quito: FLACSO.

Arciniegas, Germán (1986). Las mujeres y las horas. Santiago de Chile: Andrés Bello.

Asensio-García, Javier (Comp.) (1999). Romancero de la sierra riojana: colección de romances recopilados en los pueblos pertenecientes a la antigua mancomunidad de las Cinco Villasy Valle de Canales, Alto Najerilla. Logroño: Dirección General de Cultura.

Bastien, Pascal (2006). L'exécution publique à Paris au XVIIIe siècle. Une histoire des rituels judiciaires. Syssel: Champ Vallon.

Bastien, Pascal (2011). Une histoire de la peine de mort. Bourreaux et supplices, 1500-180o. París: Seuil. 
Botrel, Jean-François (1993). Libros, prensa y lectura en la España del siglo XIX. Madrid: Fundación Germán Sánchez Ruipérez/Pirámide.

Carbajo-Isla, María F. (2007). Muertes malas: ejecuciones en el siglo XVIII. En Etnografías de la muerte y las culturas en América Latina (pp. 75-98), coordinado por Juan Antonio Flores-Martos; Luisa Abad-González. Cuenca: Universidad Castilla-La Mancha/AECID.

Chartier, Roger (1994). "Cultura popular”. Retorno a un concepto historiográfico. Manuscrits, 12, 43-62.

Cordovez-Moure, José María (1957). Reminiscencias de Santaféy Bogotá. Madrid: Aguilar.

De Certeau, Michel (1996). La invención de lo cotidiano [Vol. I: Artes de hacer]. México: Universidad Iberoamericana.

Díaz-Díaz, Oswaldo (1962). Los Almeida. Episodios de la resistencia patriota contra el ejército pacificador de Tierra Firme. Bogotá: ABC.

Díaz-Viana, Luis (1988). La literatura de cordel como proceso: su invención y difusión en nuestro siglo. Revista de Folklore, 85, 28-36.

Elias, Norbert (1997). El proceso de la civilización: investigaciones sociogenéticas y psicogenéticas. Medellín: UNAL.

Foucault, Michel (1995). Tecnologías del yo y otros textos afines. Barcelona: Paidós.

García de Enterría, María Cruz (1973). Sociedad y poesía de cordel en el Barroco. Madrid: Taurus.

Gomis, Juan (2016). Los rostros del criminal: una aproximación a la literatura de patíbulo en España. Cuadernos de Ilustración y Romanticismo, 22, 9-33.

Gutiérrez, Rufino (1920). Monografias (Tomo I). Bogotá: Imprenta Nacional.

Ibáñez, Pedro María (2014). Crónicas de Bogotá. Bogotá: Instituto Distrital de las Artes.

Lapeskera, Ramón (1995). Crímenes en las calles de Pamplona. Pamplona: Lamia.

Lillo, Gastón; Urbina, José Leandro (2010). De independencias y revoluciones. Avatares de la modernidad en América Latina. Santiago de Chile: LOM/Universidad de Ottawa/Universidad Alberto Hurtado.

Lüsebrink, Hans-Jürgen (1982). La letteratura del patibolo. Continuità e trasformazioni tra' 600 e '80o. Quaderni Storici, 49, 285-301.

Marco, Joaquín (1977). Literatura popular en España en los siglos XVIIIy XIX (Una aproximación a los pliegos de cordel). Madrid: Taurus.

Mayorga-Ulloa, Natalia (2015). Sistema penitenciarioy carcelario en Colombia, dentro del marco de un Estado social de derecho (Tesis de especialización). Universidad Militar Nueva Granada, 
Facultad de Derecho, Especialización en Procedimiento Penal, Constitucional y Justicia Militar, Bogotá, Colombia.

O’Leary, Daniel Florencio (1879-1888). Memorias del general O'Leary [31 vol.]. Caracas: Imprenta de la Gaceta Oficial.

Ortiz-Hernández, Santiago Alejandro (2016). Viday obra del coronel Anselmo Pineda. Un estudio del coleccionismo y las redes sociales en Nueva Granada durante el siglo XIX (Tesis de pregrado). Pontificia Universidad Javeriana, Facultad de Ciencias Sociales, Bogotá, Colombia.

Parada-García, Gilberto Enrique (2014). Ley formal y ley material. La ley penaly su codificación en la construcción del Estado colombiano, 1819-1837. Ibagué: Universidad del Tolima.

Peñas-Felizzola, Aura Helena (2006). Génesis del sistema penal colombiano. Utilitarismo y tradicionalismo en el código penal neogranadino de 1837. Bogotá: Doctrina y Ley.

Pérez-Silva, Vicente (1997). Dionisia Mosquera: un crimen pasional del siglo XVIII en Popayán. Bogotá: Temas de Hoy.

Rodríguez-Sánchez, Ángel (1994). La soga y el fuego. La pena de muerte en la España de los siglos XVI y XVII. Cuadernos de Historia Moderna, 15, 13-39.

Rubio, Alfonso (2018). Memoria de un romance. La muerte a cuchillo. Horroroso y sangriento drama ocurrido entre Los Molinos y Pipaona de Ocón, provincia de Logroño, el día 29 de junio de 1885. Madrid: CSIC.

Rubio, Alfonso; Murillo-Sandoval, Juan David (2017). Historia de la edición en Colombia, 17381851. Bogotá: Instituto Caro y Cuervo.

Santos-Molano, Enrique (2011). Grandes conspiraciones en la Historia de Colombia. De los bellacos oidores de 1714 a los políticos traidores de 1867. Bogotá: Random House Mondadori.

Schechner, Richard (2011). Restauración de la conducta. En Estudios avanzados de performance (pp.31-49), editado por Diana Taylor; Marcela Fuentes. Ciudad de México: FCE/Instituto Hemisférico de Performance y Política/Tisch School of the Arts, New York University.

Sozzo, Máximo (2007). Retratando al homo criminalis. Esencialismo y diferencia en las representaciones "profanas" del delincuente en la Revista Criminal (Buenos Aires, 1873). En La ley de los profanos. Delito, justiciay cultura en Buenos Aires (1870-1940) (pp. 23-65), compilado por Lila Caimari. Buenos Aires: FCE.

Urueta, José P. (1886). Los mártires de Cartagena. Cartagena: Tipografía de Antonio Araújo L. 